CUBO A Mathematical Journal Vol.15, № 02, (65-69). June 2013

\title{
A Note on Modifications of rg-Closed Sets in Topological Spaces
}

\author{
TAKASHI NOIRI \\ 2949-1 Shiokita-Cho, Hinagu, \\ Yatsushiro-Shi, Kumamoto-Ken, \\ 869-5142 Japan. \\ t.noiri@nifty.com
}

\author{
VAleriu Popa \\ Department of Mathematics, \\ University of Bacău,, \\ 600115 Bacău, Romania, \\ vpopa@ub.ro
}

\begin{abstract}
We point out that a certain modification of regular generalized closed sets due to Palaniappan and Rao [15] means nothing to the family of semi-open sets.

\section{RESUMEN}

Destacamos que una modificación de conjuntos cerrados regulares generalizados debido a Palaniappan and Rao [15] no tiene importancia para la familia de conjuntos semiabiertos.
\end{abstract}

Keywords and Phrases: g-closed, rg-closed.

2010 AMS Mathematics Subject Classification: 54A05. 


\section{Introduction}

In 1970, Levine 11] introduced the notion of generalized closed (briefly g-closed) sets in topological spaces and showed that compactness, locally compactness, countably compactness, paracompactness, and normality etc are all g-closed hereditary. And also he introduced a separation axiom called $T_{1 / 2}$ between $T_{1}$ and $T_{0}$. Since then, many modifications of $g$-closed sets are introduced and investigated. Among them, Dontchev and Ganster [5] introduced the notion of $\mathrm{T}_{3 / 4}$-spaces which are situated between $T_{1}$ and $T_{1 / 2}$ and showed that the digital line or the Khalimsky line [9] $(\mathbf{Z}, \kappa)$ lies between $T_{1}$ and $T_{3 / 4}$.

As a modification of $\mathrm{g}$-closed sets, regular generalized closed sets are introduced and investigated by Palaniappan and Rao [15. As the further modification of g-closed sets, Gnanambal [7] introduced the notion of generalized preregular closed sets. The purpose of this note is to present some remarks concerning modifications of regular generalized closed sets.

\section{Preliminaries}

Let $(X, \tau)$ be a topological space and $A$ a subset of $X$. The closure of $A$ and the interior of $A$ are denoted by $\mathrm{Cl}(A)$ and $\operatorname{Int}(A)$, respectively. We recall some generalized open sets in topological spaces.

Definition 2.1. Let $(X, \tau)$ be a topological space. A subset $A$ of $X$ is said to be

(1) $\alpha$-open [14] if $A \subset \operatorname{Int}(\mathrm{Cl}(\operatorname{Int}(A)))$,

(2) semi-open 10 if $A \subset \mathrm{Cl}(\operatorname{Int}(A))$,

(3) preopen 12 if $A \subset \operatorname{Int}(\mathrm{Cl}(A))$,

(4) semi-preopen [2] or $\beta$-open [1] if $A \subset \mathrm{Cl}(\operatorname{Int}(\mathrm{Cl}(A)))$,

(5) b-open 3 if $A \subset \operatorname{Int}(\mathrm{Cl}(A)) \cup \operatorname{Cl}(\operatorname{Int}(A))$,

(6) regular open if $A=\operatorname{Int}(\mathrm{Cl}(A))$.

The family of all $\alpha$-open (resp. semi-open, preopen, semi-preopen, b-open, regular open) sets in $(X, \tau)$ is denoted by $\tau^{\alpha}$ (resp. $\left.\mathrm{SO}(X), \operatorname{PO}(X), \operatorname{SPO}(X), \operatorname{BO}(X), \operatorname{RO}(X, \tau)\right)$.

For generalizations of open sets defined above, the following relations are well known:

\section{DIAGRAM I}

$$
\begin{gathered}
\text { open } \Rightarrow \text {-open } \Rightarrow \text { preopen } \\
\Downarrow \\
\Downarrow \\
\text { semi-open } \Rightarrow \text { b-open } \Rightarrow \text { semi-preopen }
\end{gathered}
$$

Definition 2.2. Let $(X, \tau)$ be a topological space. A subset $A$ of $X$ is said to be $\alpha$-closed 13 . (resp. semi-closed [4], preclosed [12, semi-preclosed [2, b-closed [3]) if the complement of $A$ is $\alpha$-open (resp. semi-open, preopen, semi-preopen, b-open). 
Definition 2.3. Let $(X, \tau)$ be a topological space and $A$ a subset of $X$. The intersection of all $\alpha$-closed (resp. semi-closed, preclosed, semi-preclosed, $b$-closed) sets of $X$ containing $A$ is called the $\alpha$-closure [13] (resp. semi-closure [4, preclosure [6], semi-preclosure [2], b-closure [3]) of $A$ and is denoted by $\alpha \mathrm{Cl}(A)$ (resp. $\mathrm{sCl}(A), \operatorname{pCl}(A), \operatorname{spCl}(A), b \mathrm{bl}(A)$ ).

Definition 2.4. Let $(X, \tau)$ be a topological space. A subset $A$ of $X$ is said to be

(1) generalized closed (briefly g-closed) [11] if $\mathrm{Cl}(\mathrm{A}) \subset \mathrm{U}$ whenever $\mathrm{A} \subset \mathrm{U}$ and $\mathrm{U} \in \tau$,

(2) regular generalized closed (briefly rg-closed) 15] if $\mathrm{Cl}(\mathrm{A}) \subset \mathrm{U}$ whenever $\mathrm{A} \subset \mathrm{U}$ and $\mathrm{U} \in \mathrm{RO}(\mathrm{X}, \tau)$,

(3) generalized preregular closed (briefly gpr-closed) 7] if $\mathrm{pCl}(\mathrm{A}) \subset \mathrm{U}$ whenever $\mathrm{A} \subset \mathrm{U}$ and $\mathrm{U} \in \mathrm{RO}(\mathrm{X}, \tau)$.

For generalizations of closed sets defined above, the following relations are well known:

\section{DIAGRAM II}

closed $\Rightarrow$ g-closed $\Rightarrow$ rg-closed $\Rightarrow$ gpr-closed

\section{Modifications of $\mathrm{rg}$-closed sets}

First we shall define a modification of rg-closed sets.

Definition 3.1. Let $(X, \tau)$ be a topological space. A subset $A$ of $X$ is said to be regular generalized $\alpha$-closed (briefly rg $\alpha$-closed) if $\alpha \mathrm{Cl}(\mathrm{A}) \subset \mathrm{U}$ whenever $\mathrm{A} \subset \mathrm{U}$ and $\mathrm{U} \in \mathrm{RO}(\mathrm{X}, \tau)$.

Lemma 3.2. If $A$ is a subset of $(X, \tau)$, then $\tau^{\alpha}-\operatorname{Int}\left(\tau^{\alpha}-\mathrm{Cl}(A)\right)=\operatorname{Int}(\mathrm{Cl}(A))$.

Proof. This is shown in Corollary 2.4 of $[8]$.

Lemma 3.3. Let $V$ be a subset of a topological space $(X, \tau)$. Then $\mathrm{V} \in \mathrm{RO}(\mathrm{X}, \tau)$ if and only if $\mathrm{V} \in \operatorname{RO}\left(X, \tau^{\alpha}\right)$.

Proof. This is an immediate consequence of Lemma 3.2.

Theorem 3.4. A subset $A$ of a topological space $(X, \tau)$ is $\mathrm{rg} \alpha$-closed in $(X, \tau)$ if and only if $A$ is $\mathrm{rg}$-closed in the topological space $\left(\mathrm{X}, \tau^{\alpha}\right)$.

Proof. Necessity. Suppose that $A$ is $r g \alpha$-closed in $(X, \tau)$. Let $A \subset V$ and $V \in R O\left(X, \tau^{\alpha}\right)$. By Lemma 3.3, $\mathrm{V} \in \mathrm{RO}(\mathrm{X}, \tau)$ and we have $\tau_{\alpha}-\mathrm{Cl}(\mathrm{A})=\alpha \mathrm{Cl}(\mathrm{A}) \subset \mathrm{V}$. Therefore, $\mathrm{A}$ is rg-closed in $\left(X, \tau^{\alpha}\right)$.

Sufficiency. Suppose that $A$ is rg-closed in $\left(X, \tau^{\alpha}\right)$. Let $A \subset V$ and $V \in \operatorname{RO}(X, \tau)$. By Lemma 3.3, $\mathrm{V} \in \operatorname{RO}\left(X, \tau^{\alpha}\right)$ and hence $\alpha \mathrm{Cl}(\mathrm{A})=\tau_{\alpha}-\mathrm{Cl}(\mathrm{A}) \subset \mathrm{V}$. Therefore, $\mathrm{A}$ is $\operatorname{rg} \alpha$-closed in $(\mathrm{X}, \tau)$. 
Remark 3.5. It turns out that, by Therem 3.4, we can not obtain the essential notion even if we replace $\mathrm{Cl}(\mathrm{A})$ in Definition $2.4(2)$ with $\alpha \mathrm{Cl}(\mathrm{A})$.

Next, we try to replace $\mathrm{Cl}(\mathrm{A})$ in Definition $2.4(2)$ with $\mathrm{sCl}(\mathrm{A})$.

Lemma 3.6. Let $(\mathrm{X}, \tau)$ be a topological space. If $\mathrm{A} \subset \mathrm{V}$ and $\mathrm{V} \in \mathrm{RO}(\mathrm{X}, \tau)$, then $\mathrm{sCl}(\mathrm{A}) \subset \mathrm{V}$.

Proof. Let $A \subset V$ and $V \in \operatorname{RO}(X, \tau)$. Then we have $\operatorname{sCl}(A) \subset \operatorname{sCl}(V)=V \cup \operatorname{Int}(\operatorname{Cl}(V))=V$ and hence $\operatorname{sCl}(A) \subset \mathrm{V}$.

Remark 3.7. (1) Lemma 3.6 shows that in case $\mathrm{SO}(X, \tau)$ the condition " $\mathrm{sCl}(A) \subset \mathrm{V}$ whenever $\mathrm{A} \subset \mathrm{V}$ and $\mathrm{V} \in \mathrm{RO}(\mathrm{X}, \tau)$ " does not define a subset like regualr generalized semi-closed sets.

(2) By Diagram I, $\mathrm{SO}(X) \subset \mathrm{BO}(X) \subset \mathrm{SPO}(X)$ and hence $\operatorname{spCl}(A) \subset \mathrm{bCl}(A) \subset \operatorname{sCl}(A)$ for any subset $A$ of $X$. Therefore, we can not obtain any notions even if we replace $\mathrm{Cl}(A)$ in Definitiion $2.4(2)$ with $\operatorname{sCl}(A), b C l(A)$ or $\operatorname{spCl}(A)$.

Received: October 2010. Accepted: September 2012.

\section{References}

[1] M. E. Abd El-Monsef, S. N. El-Deep and R. A. Mahmoud, $\beta$-open sets and $\beta$-continuous mappings, Bull. Fac. Sci. Assiut Univ., 12 (1983), 77-90.

[2] D. Andrijević, Semi-preopen sets, Mat. Vesnik, 38 (1986), 24-32.

[3] D. Andrijević, On b-open sets, Mat. Vesnik, 48 (1996), 59-64.

[4] S. G. Crossley and S. K. Hildebrand, Semi-closure, Texas J. Sci., 22 (1971), 99-112.

[5] J. Dontchev and M. Ganster, On $\delta$-generalized closed sets and $\mathrm{T}_{3 / 4}$-spaces, Mem. Fac. Sci. Kochi Univ. Ser. A Math., 17 (1996), 15-31.

[6] S. N. El-Deeb, I. A. Hasanein, A. S. Mashhour and T. Noiri, On p-regular spaces, Bull. Math. Soc. Sci. Math. R. S. Roumanie, 27(75) (1983), 311-315.

[7] Y. Gnanambal, On generalized preregular closed sets in topological spaces, Indian J. Pure Appl. Math., 28 (1997), 351-360.

[8] D. S. Janković, A note on mappings of extremally disconnected spaces, Acta Math. Hungar., 46 (1985), 83-92.

[9] E. D. Khalimsky, R. Kopperman and P. R. Meyer, Computer graphics and connected topologies on finite ordered sets, Topology Appl., 36 (1990), 1-17. 
[10] N. Levine, Semi-open sets and semi-continuity in topological spaces, Amer. Math. Monthly, 70 (1963), 36-41.

[11] N. Levine, Generalized closed sets in topology, Rend. Circ. Mat. Palermo (2), 19 (1970), 89-96.

[12] A. S. Mashhour, M. E. Abd El-Monsef and S. N. El-Deep, On precontinuous and weak precontinuous mappings, Proc. Math. Phys. Soc. Egypt, 53 (1982), 47-53.

[13] A. S. Mashhour, I. A. Hasanein and S. N. El-Deeb, $\alpha$-continuous and $\alpha$-open mappings, Acta Math. Hungar., 41 (1983), 213-218.

[14] O. Njåstad, On some classes of nearly open sets, Pacific J. Math., 15 (1965), 961-970.

[15] N. Palaniappan and K. C. Rao, Regular generalized closed sets,Kyungpook Math. J., 33 (1993), 211-219. 